\title{
Tipos e concentrações de citocinina na multiplicação in vitro de pitangueira
}

\author{
Types and concentrations of cytokinin on in vitro multiplication of 'pitangueira'
}

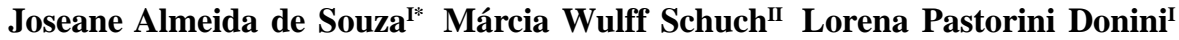 \\ Mirian de Farias Ribeiro"
}

\begin{abstract}
O trabalho teve como objetivo avaliar o efeito de diferentes tipos e concentrações de citocinina na multiplicação in vitro de pitangueira. Os tratamentos constituíram-se de diferentes concentrações de citocinina adicionada ao meio de cultura (zero; cinco; dez $\mu M$ ) e três diferentes citocininas (BAP; $2 i P$; zeatina). O meio utilizado foi WPM suplementado com $100 \mathrm{mg}^{-1}$ de mio-inositol, $30 \mathrm{~g} L^{-1}$ de sacarose e solidificado com ágar na concentração de seisg $L^{-1}$. Segmentos caulinares com três ou quatro gemas, sem o ápice, foram incubados em frascos contendo $30 \mathrm{~mL}$ de meio. Após a inoculação, os explantes foram mantidos em sala de crescimento com 16 horas de fotoperiodo com radiação de $27 \mu \mathrm{mol} \mathrm{m}^{-2} \mathrm{~s}^{-1}$ e temperatura de $25 \pm 2{ }^{\circ} \mathrm{C}$. Aos 45 dias de cultivo, foram avaliados o número médio de folhas, o número médio de brotações e o comprimento das brotações. Os resultados permitiram concluir que, para a multiplicação in vitro de pitangueira, deve-se utilizar a menor concentração de BAP, a qual apresentou resultado satisfatório e tem menor custo.
\end{abstract}

Palavras-chave: micropropagação, Eugenia uniflora L., frutas nativas.

\section{ABSTRACT}

This research aimed to assess the effect of different types (BAP, 2ip, zeatin) and concentrations (zero; five; ten $\mu M$ ) of cytokinin on in vitro multiplication of 'Pitangueira'. The different concentrations were added to the culture medium. The medium used was WPM enriched with 100mg $L^{-1}$ of myo-inositol, $30 \mathrm{~g} \mathrm{~L}^{-1}$ of sucrose and solidified with agar at sixg $L^{-1}$ concentration. Stem segments with 3 or 4 buds, without apical meristem, were incubated into flasks containing $30 \mathrm{~mL}$ of medium. After inoculation, the explants were kept in growth room under 16 hours photoperiod with $27 \mu \mathrm{mol} \mathrm{m}^{-2} \mathrm{~s}^{-1}$ radiation and temperature of $25 \pm 2^{\circ} \mathrm{C}$. At $45^{\text {th }}$ days of cultivation, the average number of leaves and shoots and the shoot length were measured. The results showed that by using lesser concentration of BAP there was better performance and less costs for in vitro multiplication of 'Pitangueira'.

Key words: micropropagation, Eugenia uniflora L., native fruits.

O Brasil é um dos principais centros de diversidade genética de espécies frutíferas. No Sul do Brasil existe uma grande diversidade de fruteiras nativas, entre as quais se destaca a pitangueira (Eugenia uniflora L.), pertencente à família Mirtácea (RASEIRA et al., 2004). O potencial de utilização desta espécie é ressaltado quando se considera que o fruto de sabor exótico é rico em vitaminas, no entanto, a variabilidade genética pode determinar algumas diferenças nesses valores (BEZERRA et al., 2000).

Os principais métodos de obtenção de mudas desta espécie envolvem sementes, enxertia e estaquia, sendo que o processo mais usual é o realizado por meio de sementes. Em decorrência dessa prática, os pomares formados resultam em plantas desuniformes, de baixa produtividade e com frutos de má qualidade (BEZERRA et al., 2002; BEZERRA, et al., 2004). No entanto, (BEZERRA et al., 2000) afirmam que à medida que a pitangueira vai se tornando uma cultura de interesse comercial, o plantio a partir de sementes deve dar lugar à propagação vegetativa de variedades

IPrograma de Pós-graduação em Agronomia, área de concentração em Fruticultura de Clima Temperado, Faculdade de Agronomia Eliseu Maciel (FAEM), Universidade Federal de Pelotas (UFPel), CP 354, 96010-900, Pelotas, RS. E-mail: joseas@ufpel.tche.br. *Autor para correspondência.

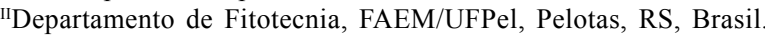


selecionadas, assegurando a formação de pomares com populações de plantas homogêneas. O cultivo in vitro, por meio da micropropagação, é um método viável de propagação podendo assegurar a uniformidade dos pomares, além de possibilitar a produção de mudas com alta sanidade e acelerar os métodos de propagação convencional, por meio do rejuvenescimento in vitro.

Um dos objetivos da micropropagação é a maximização da multiplicação de gemas (ERIG et al., 2002), podendo ser alcançado na fase de multiplicação in vitro. Fatores como meio de cultura, tipo e concentração de citocininas são importantes de serem observados nesta fase (GRATTAPAGLIA \& MACHADO, 1998). A citocinina é indispensável nesta fase para a quebra da dominância apical e a indução da proliferação de gemas axilares (HU \& WANG, 1983). Segundo SCHUCH \& ERIG (2005), as concentrações de citocininas para a multiplicação estão entre $0,1 \mathrm{e}$ $5,0 \mathrm{mg} \mathrm{L}^{-1}$ e entre as citocininas comercialmente disponíveis a benzilaminopurina (BAP), geralmente apresenta melhores resultados.

A micropropagação de pitangueira é ainda incipiente. No entanto, alguns trabalhos iniciais apresentam suporte para otimização de protocolos de multiplicação desta espécie. OLIVIER (1997) observou que o meio MS com $100 \%$ dos seus sais e vitaminas adicionado de $1,2 \mu \mathrm{M}$ de BAe $0,3 \mu \mathrm{M}$ de ANA apresentou baixa taxa de multiplicação de pitangueira. SOUZA et al. (2007) concluíram que a utilização de explantes de $1,5 \mathrm{~cm}$ de comprimento e a utilização de ágar como solidificante no meio de cultura proporcionou um maior estabelecimento in vitro desta espécie.

Dessa forma, o objetivo do presente trabalho foi avaliar o efeito de diferentes tipos e concentrações de citocinina na multiplicação in vitro de pitangueira.

O trabalho foi realizado no Laboratório de Micropropagação de Plantas Frutíferas, Departamento de Fitotecnia da Faculdade de Agronomia Eliseu Maciel, da Universidade Federal de Pelotas, RS. O material vegetal utilizado foram mudas de pitangueira, cedidas pela Embrapa-Clima Temperado. Segmentos caulinares com três ou quatro gemas $(0,5 \mathrm{a} 1,0 \mathrm{~cm})$, sem o ápice, provenientes de brotações de pitangueira cultivadas in vitro, foram utilizados como explante.

$\mathrm{O}$ delineamento experimental foi inteiramente casualizado, no esquema fatorial $3 \times 3 \mathrm{com}$ quatro repetições por tratamento. Cada repetição composta de um frasco de $250 \mathrm{~mL}$ com cinco explantes. Os tratamentos foram constituídos por diferentes concentrações de citocinina adicionada ao meio de cultura (zero; $5 ; 10 \mu \mathrm{M}$ ) e três citocininas (6Benzilaminopurina; Isopenteniladenina; zeatina), totalizando nove tratamentos.
O meio de cultura utilizado foi o WPM (LLOYD \& MCCOWN, 1981), suplementado com $100 \mathrm{mg} \mathrm{L}^{-1}$ de mio-inositol, $30 \mathrm{~g} \mathrm{~L}^{-1} \mathrm{de}$ sacarose e solidificado com $6 \mathrm{~g} \mathrm{~L}^{-1}$ de ágar, sendo o $\mathrm{pH}$ ajustado para 5,8 antes da inclusão do solidificante e, posteriormente, autoclavado a $121^{\circ} \mathrm{C}$ e $1,5 \mathrm{~atm}$ por 20 minutos. Foram utilizados frascos com $30 \mathrm{~mL}$ de meio de cultura.

Após a inoculação, os explantes foram mantidos em sala de crescimento com fotoperíodo de 16 horas diárias de luz, temperatura de $25 \pm 2^{\circ} \mathrm{C}$ e densidade de fluxo de fótons do período de luz de $27 \mu \mathrm{mol} \mathrm{m}^{-2} \mathrm{~s}^{-1}$.

Aos 45 dias de cultivo, foram avaliados o número médio de folhas, o número médio de brotações e o comprimento das brotações. Os dados foram submetidos à análise de variância e as médias dos tratamentos comparadas estatisticamente pelo teste de Duncan. Os dados de número médio de folhas e o número médio de brotações foram transformados segundo raiz quadrada de $\mathrm{x}+0,5$, em que $\mathrm{x}$ é o número obtido.

Para a variável número médio de gemas, houve efeito da concentração de citocinina, sendo que a ausência do fitoregulador foi inferior aos demais tratamentos (Tabela 1). Estes resultados estão de acordo com GRATTAPAGLIA\& MACHADO (1998), que mostram que a adição de citocininas é favorável à multiplicação in vitro de algumas espécies. Também ALI \& LÜDDERS (2001) observaram maior taxa de multiplicação, em explantes de Psidium guajava L., utilizando BAP na concentração de 2,2-4,4 $\mu \mathrm{M}$ após quatro semanas de cultivo, comprovando a necessidade da adição de citocininas exógenas para a maioria das espécies.

Para a variável número médio das brotações, observou-se interação entre o tipo e a concentração de citocinina, sendo que a BAP apresentou os melhores resultados, seguida da zeatina e o $2 \mathrm{iP}$ apresentou os piores resultados (Tabela 1). Resultados semelhantes foram encontrados por ERIG et al. (2002), em que o maior número de brotações em explantes de amorapreta foi obtido com 2 e $4 \mu \mathrm{M}$ de BAP. Além disso CHAVES et al. (2005) verificaram maior número de brotações, em explantes de Physalis peruviana L. utilizando 1,3 $\mu \mathrm{M}$ de BAP. BERTONI \& BIRICOLTI(1996) observaram que ocorreu proliferação de parte aérea em Feijoa sellowiana (Berg.) quando adicionado BA ao meio de cultivo, mas não houve diferença no número de brotações quando utilizaram concentrações de 2,5 a $10,0 \mu \mathrm{M}$ de BA. MOHAMED-YASSEEN et al. (1995) obtiveram maior número de brotações em segmentos nodais de $\boldsymbol{P}$. guajava, utilizando BA na concentração de $4,4 \mu \mathrm{M}$. Esta diversidade de resultados está de acordo com CALDAS et al. (1998), os quais sugerem 
Tabela 1 - Número médio de gemas e número médio das brotações em explantes de pitangueira após 45 dias de cultivo in vitro em meio WPM na presença de diferentes tipos e concentrações de citocinina. UFPel, Pelotas, RS. 2006.

\begin{tabular}{|c|c|c|c|c|}
\hline \multirow{2}{*}{ Concentrações de citocininas $(\mu \mathrm{M})$} & \multirow{2}{*}{$\mathrm{N}^{\mathrm{o}}$ médio de gemas } & \multicolumn{3}{|c|}{ 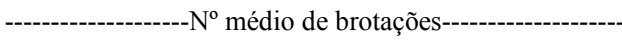 } \\
\hline & & BAP & ZEATINA & $2 \mathrm{iP}$ \\
\hline Dez & $3,96 \mathrm{a}^{*}$ & $2,44 \mathrm{aA}$ & $1,80 \mathrm{aB}$ & $1,12 \mathrm{aC}$ \\
\hline Cinco & $3,93 \mathrm{a}$ & $2,35 \mathrm{aA}$ & $1,53 \mathrm{aB}$ & $1,05 \mathrm{aC}$ \\
\hline Zero & $3,24 \mathrm{~b}$ & $1,20 \mathrm{bA}$ & $1,10 \mathrm{bA}$ & $1,19 \mathrm{aA}$ \\
\hline
\end{tabular}

*Médias não seguidas de mesma letra minúscula nas colunas e maiúscula nas linhas diferem entre si pelo teste de Duncan em nível de $5 \%$ de probabilidade de erro.

que a composição e a concentração de hormônios no meio de cultura são fatores determinantes no crescimento e no padrão de desenvolvimento na maioria dos sistemas de cultura de tecidos.

Para a variável comprimento médio das brotações, não foi verificada diferença estatística para os fatores avaliados, verificando-se comprimento médio variando de $0,32 \mathrm{~cm}$ a $0,45 \mathrm{~cm}$ de acordo com os tratamentos.

Na multiplicação in vitro de pitangueira, deve ser utilizada a menor concentração da citocinina BAP, que apresentou resultado satisfatório e tem menor custo.

\section{REFERÊNCIAS}

ALI, M.A.; LÜDDERS, P. In vitro culture and its application on the cloning of guava (Psidium guajava L.). Jounal of Applied Botany, Göttingen, v.75, p.164-167, 2001.

BERTONI, P.; BIRICOLTI, S. Preliminary observations on the in vitro behaviour of Feijoa sellowiana (Berg.) seedlings. Rivista di Frutticoltura e di Ortofloricoltura, Bologna, v.58, n.4, p.61-64, 1996.

BEZERRA, J.E.F. et al. Pitanga (Eugenia uniflora L.). Jaboticabal: FUNEP, 2000. 30p. (Série Frutas Nativas, 1).

BEZERRA, J.E.F. et al. Propagação de genótipos de pitangueira (Eugenia uniflora L.) pelo método de enxertia de garfagem no topo em fenda cheia. Revista Brasileira de Fruticultura, Jaboticabal, v.24, n.1, p.160-162, 2002.

BEZERRA, J.E.F. et al. Comportamento da pitangueira (Eugenia uniflora L.) sob irrigação na região do vale do rio moxotó, Pernambuco. Revista Brasileira de Fruticultura, Jaboticabal, v.26, n.1, p.177-179, 2004.

CALDAS, L.S. et al. Meios nutritivos. In: TORRES, A.C. et al. Cultura de tecidos e transformação genética de plantas. Brasília: Embrapa-SPI/Embrapa-CNPH, 1998. p.183-260.

CHAVES, A.C. et al. Estabelecimento e multiplicação in vitro de Physalis peruviana L. Ciência Agrotécnica, Lavras, v.29, n.6, p.1281-1287, 2005.

ERIG, A.C. et al. 6-benzilaminopurina e ácido indolbutírico na multiplicação in vitro da amoreira-preta (Rubus idaeus L.), cv. Tupy. Ciência Rural, Santa Maria, v.32, n.5, p.765-770, 2002.

GRATTAPAGLIA, D.; MACHADO, M.A. Micropropagação. In: TORRES, A.C. et al. Cultura de tecidos e transformação genética de plantas. Brasília: Embrapa-SPI/Embrapa-CNPH, 1998. p.183-260.

HU, C.Y.; WANG, P.J. Meristem, shoot tip and bud culture. In: EVANS, D.A. et al. Handbook of plant cell culture: techniques for propagation and breeding. New York: Macmillan, 1983. p.117-227.

LLOYD, G.; McCOWN, B. Commercially feasible micropropagation of montain laurel, Kalmia latifolia, by use of shoot tip culture. Combined Proceedings of the International Plant Propagator's Society, v.30, p.421$327,1981$.

MOHAMED-YASSEEN, Y. et al. In vitro shoot proliferation and propagation of guava (Psidium guajava L.) from germinated seedlings. Plant Cell Reports, Heidelberg, v.14, p.525-528, 1995.

OLIVER, J. J. Initiation of the Surinam cherry (Eugenia uniflora) in tissue culture. Inligtingsbulletin Instituut vir Tropiese en Sbtropiese Gewasse, n.295, p.5-6, 1997.

RASEIRA, M.C.B. et al. Espécies frutíferas nativas do sul do Brasil. Pelotas: Embrapa Clima Temperado, 2004. 122p.

SCHUCH, M.W.; ERIG, A.C. Micropropagação de plantas frutíferas. In. FACHINELO, J.C. et al. Propagação de plantas frutíferas. Brasília: Embrapa Informações Tecnológicas, 2005. p.155-173.

SOUZA, J.A. et al. Solifificante no meio de cultura e tamanho do explante no estabelecimento da propagação in vitro de pitangueira (Eugenia uniflora L.). Revista Brasileira de Agrociência, Pelotas, v.13, n.1, p.115-118, 2007. 